University of Wollongong

Research Online

Faculty of Business - Papers (Archive)

Faculty of Business and Law

$1-1-2011$

How satisfaction modifies the strength of the influence of perceived service quality on behavioral intentions

Shyh Jane Li

National Sun Yat-Sen University

Yu-Ying Huang

National Sun Yat-Sen University, y.y.huang84@hotmail.com

Miles Yang

University of New South Wales, milesy@uow.edu.au

Follow this and additional works at: https://ro.uow.edu.au/buspapers

Part of the Business Commons

Research Online is the open access institutional repository for the University of Wollongong. For further information contact the UOW Library: research-pubs@uow.edu.au 


\title{
How satisfaction modifies the strength of the influence of perceived service quality on behavioral intentions
}

\begin{abstract}
Purpose: The existence and form of interaction effects between service quality and satisfaction are still uncertain. The main purpose of this study is to examine whether satisfaction moderates the relationship between service quality and behavioral intentions. Design/methodology/approach: A structured questionnaire was distributed to the out-patients of 12 regional hospitals (the middle level) in Taiwan. Findings: The findings show that the forms of moderators played by satisfaction are not always the same under different dimensions of service quality (i.e. reliability, responsiveness, assurance, and empathy). Satisfaction positively moderates the influence of reliability/empathy on behavioral intentions, but negatively moderates the relationships between responsiveness/assurance and behavioral intentions. Originality/value: This study reveals the moderating role of satisfaction in the translation from service quality to behavioral intentions in health care services. Moreover, the natures of the moderating effects are not the same for different service quality dimensions. Emerald Group Publishing Limited.
\end{abstract}

\section{Keywords}

influence, perceived, service, quality, modifies, behavioral, satisfaction, intentions, strength

\section{Disciplines \\ Business}

\section{Publication Details}

Li, S., Huang, Y. \& Yang, M. M. (2011). How satisfaction modifies the strength of the influence of perceived service quality on behavioral intentions. Leadership in Health Services, 24 (2), 91-105. 


\section{Emerald Insight}

\section{Leadership in Health Services}

How satisfaction modifies the strength of the influence of perceived service quality on

behavioral intentions

Shyh-Jane Li Yu-Ying Huang Miles M. Yang

\section{Article information:}

To cite this document:

Shyh-Jane Li Yu-Ying Huang Miles M. Yang, (2011),"How satisfaction modifies the strength of the influence of perceived service quality on behavioral intentions", Leadership in Health Services, Vol. 24 Iss 2 pp. 91 105

Permanent link to this document:

http://dx.doi.org/10.1108/17511871111125675

Downloaded on: 31 March 2016, At: 20:07 (PT)

References: this document contains references to 42 other documents.

To copy this document: permissions@emeraldinsight.com

The fulltext of this document has been downloaded 2394 times since 2011*

\section{Users who downloaded this article also downloaded:}

(2012),"The influence of the quality of the physical environment, food, and service on

restaurant image, customer perceived value, customer satisfaction, and behavioral intentions",

International Journal of Contemporary Hospitality Management, Vol. 24 Iss 2 pp. 200-223 http://

dx.doi.org/10.1108/09596111211206141

(2013),"Hospital service quality and its effects on patient satisfaction and behavioural intention",

Clinical Governance: An International Journal, Vol. 18 Iss 3 pp. 238-254 http://dx.doi.org/10.1108/

CGIJ-05-2012-0016

(2014),"The effects of customer satisfaction, perceived value, corporate image and service quality on behavioral intentions in gaming establishments", Asia Pacific Journal of Marketing and Logistics, Vol. 26 Iss 4 pp. 540-565 http://dx.doi.org/10.1108/APJML-03-2014-0049

UNIVERSITY OF
WOLLONGONG

Access to this document was granted through an Emerald subscription provided by emerald-srm:235887 []

\section{For Authors}

If you would like to write for this, or any other Emerald publication, then please use our Emerald for Authors service information about how to choose which publication to write for and submission guidelines are available for all. Please visit www. emeraldinsight.com/ authors for more information.

\section{About Emerald www.emeraldinsight.com}

Emerald is a global publisher linking research and practice to the benefit of society. The company manages a portfolio of more than 290 journals and over 2,350 books and book series volumes, as well as providing an extensive range of online products and additional customer resources and services.

Emerald is both COUNTER 4 and TRANSFER compliant. The organization is a partner of the Committee on Publication Ethics (COPE) and also works with Portico and the LOCKSS initiative for digital archive preservation. 
*Related content and download information correct at time of download. 


\section{How satisfaction modifies the strength of the influence of perceived service quality on behavioral intentions}

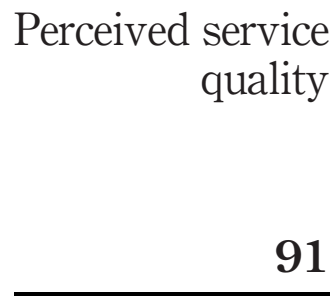

Shyh-Jane Li

Sense Team Creativity Consulting Company, Kaohsiung, Taiwan, and the Department of Business Management, National Sun Yat-Sen University, Kaohsiung, Taiwan

Yu-Ying Huang

Management Department, Antai Tian-Sheng Memorial Hospital, Taiwan, and the Department of Business Management, National Sun Yat-Sen University,

Kaohsiung, Taiwan, and

Miles M. Yang

Australian School of Business, The University of New South Wales,

Sydney, Australia

\begin{abstract}
Purpose - The existence and form of interaction effects between service quality and satisfaction are still uncertain. The main purpose of this study is to examine whether satisfaction moderates the relationship between service quality and behavioral intentions.

Design/methodology/approach - A structured questionnaire was distributed to the out-patients of 12 regional hospitals (the middle level) in Taiwan.

Findings - The findings show that the forms of moderators played by satisfaction are not always the same under different dimensions of service quality (i.e. reliability, responsiveness, assurance, and empathy). Satisfaction positively moderates the influence of reliability/empathy on behavioral intentions, but negatively moderates the relationships between responsiveness/assurance and behavioral intentions. Originality/value - This study reveals the moderating role of satisfaction in the translation from service quality to behavioral intentions in health care services. Moreover, the natures of the moderating effects are not the same for different service quality dimensions.
\end{abstract}

Keywords Customer services quality, Customer satisfaction, Health services, Health care, Taiwan

Paper type Research paper

\section{Introduction}

The relationships among perceived service quality, satisfaction, and behavior intentions are multifaceted (Bou-Llusar et al., 2001). Perceived service quality has been demonstrated to directly and positively affect patients' satisfaction, whereas much evidence shows that satisfaction mediates the relationship between service quality and behavioral intentions (see González et al., 2007; Olsen, 2002; Wu et al., 2008). Both direct and indirect effects are found in different industries, but the existence of moderating effect, which presents numerous contradictory empirical evidence (Baker and Taylor, 1997; Bou-Llusar et al., 2001; Lin, 2005), is still uncertain.
Received 27 July 2010 Revised 23 September 2010

10 October 2010

Accepted 25 October 2010 


\section{LHS}

24,2

92
In practice, high service quality does not guarantee the possibility of high satisfaction or positive behavior intentions. Sound physical environments or sufficient equipments, for example, certainly match customers' expectations but cannot offset a displeased experience with a long waiting time. Patients may be satisfied with core services (e.g. doctors' diagnoses), but the poor quality for supplement services (e.g. traffic inconvenience, slow processing speed in the payment counter or pharmacy, and so on) will give patients bad impression. These facts may be due to a lack of regarding that the relationship between service quality and satisfaction is nonlinear, and the existence of moderating effect needs to be considered.

The importance of the moderating effect arises from its ability to modify the form and/ or strength of the relationships between relevant independent variables and dependent variables (Sharma et al., 1981). For service managers, the moderating relationship means that the degree of satisfaction/dissatisfaction with the service experience would change the extent to which prior perceived service quality remain a good predictor of patient intentions (Fullerton and Taylor, 2002). Checking the existence of the moderating effect is helpful to understand whether the relationship between perceived service quality and behavioral intentions varies depending on satisfaction and to know "when" or "for whom" service quality is strongly related to behavioral intensions (Frazier et al., 2004).

This study tries to depict the moderating effect of satisfaction on the relationships between service quality and behavioral intentions in the context of the competitive health care system in Taiwan. This study attempts to provide empirical evidence for two issues:

(1) Is there any moderating effect of satisfaction on the relationships between service quality and behavioral intentions?

(2) If the moderating effect exists, is the nature of the moderating effect the same across different service quality dimensions?

The framework of this analysis is first to introduce the background of Taiwan's healthcare services and review the literature that discuss the relationships among service quality, satisfaction, and behavioral intentions. Next, the survey instrument and data collection are described. The article ends with a discussion of the results and practical implications when planning improvement strategies within healthcare services.

\section{Literature review}

\subsection{A comparison of Taiwan's healthcare services}

Renewed debate about health insurance coverage in the USA has attracted worldwide attention to Taiwan's health care system, because of its relatively low costs and short waiting times (Wen et al., 2008).

Taiwan's government has launched a National Health Insurance (NHI) program in 1995, offering a comprehensive, unified, universal, and low-payment health insurance program to citizens. The healthcare providers are divided into four levels by the number of beds and healthcare proficiency:

(1) academic medical centers (the highest level: minimum 500 beds);

(2) regional hospital (the middle level: minimum 250 beds);

(3) district hospital (the lowest level: minimum 20 beds); and

(4) physician clinics and dental clinics. 
All academic medical centers and the majority of regional hospitals are teaching hospitals, which normally enjoy higher priority in patients' opinions.

Unlike the managed care models in the USA. or other Western countries, the

Perceived service absence of a referral system and the completely free choice of providers in Taiwan have provided great incentives for patients to go "doctor shopping" (Wu et al., 2008). Most patients like to purchase healthcare services from hospitals rather than from family doctors or clinics, even for minor illnesses. The increasing frequency of going to hospitals and the "doctor shopping" pattern have resulted in the increases in the number of hospitals in Taiwan and the competition between hospitals has become quite severe. As health care services get more competitive, managers are increasingly interested in exploring how patients perceive their care quality, form their satisfaction levels, and generate their behavioral intentions.

\subsection{Service quality}

Service quality is defined as how well the service meets or exceeds the customers' expectations on a consistent basis (Parasuraman et al., 1985). Service quality, unlike product quality, is hard to define and measure because of the inter-relationship of user expectations and the impact of specific features of service such as intangibility, inseparability, heterogeneity, and perishability (Parasuraman et al., 1985; Zeithaml et al., 2006). The Service Quality Gaps Model and the SERVQUAL scale proposed by Parasuraman et al. $(1985,1988)$ are widely accepted tools for measuring service quality (Ladhari, 2008). In healthcare settings, two tools are also popular to assess service quality in a number of service categories such as acute care hospital, independent dental offices, at AIDS service agencies, with physicians and nurses, and hospitals (Taner and Antony, 2006).

\subsection{Satisfaction}

Satisfaction reflects the degree to which a customer believes that the use of a service evokes positive feelings (Rust and Oliver, 1994), and many studies have suggested that service quality and satisfaction are distinct constructs (Wu et al., 2008). A main view on this issue is that service quality represents a cognitive judgment, whereas satisfaction is a more affect-laden evaluation (Gooding, 1995; Oliver, 1993).

Distinguishing between service quality as a cognitive construct and satisfaction as an affective construct suggests a causal order, that positions service quality as an antecedent to satisfaction (Goldstein and Schweikhart, 2002; Oliver, 1993; Rust and Oliver, 1994). Empirical evidence supports this causal linkage shown in health care settings (Bowers et al., 1994; Reidenbach and Sandifer-Smallwood, 1990; Woodside et al., 1989).

\subsection{The relationships among service quality, satisfaction, and behavioral intentions}

The effect of service quality on behavioral intentions takes on different forms: direct effect, indirect effect through satisfaction, or moderating effect by satisfaction (Bou-Llusar et al., 2001).

For the direct effect, many studies in different industries have shown that service quality is an antecedent to behavioral intentions (see Boshoff and Gray, 2004; Bou-Llusar et al., 2001; Parasuraman et al., 1985, 1988; Zeithaml et al., 1996;). In health care settings, much evidence also shows that the direct impact exists (Gooding, 1995; O’Connor et al., 2000; Wu et al., 2008). 
LHS

24,2

94
Regarding the mediating effect between perceived service quality and behavioral intentions, customer satisfaction is generally considered as a mediator (Bou-Llusar et al., 2001). The conceptual nature of this relationship suggests that satisfaction is a more relevant predictor of behavioral intentions than service quality (Fullerton and Taylor, 2002). Evidence of the mediating effect of satisfaction has been found in many service industries including health care settings (e.g. O'Connor et al., 1991; Shemwell et al., 1998; Zeithaml et al., 1996),

Both the direct and indirect effects are based on the assumption that the relationships among the three constructs are linear (Taylor and Baker, 1994). There should be nonlinear relationship between perceived service quality and satisfaction (Falk et al., 2010; Pollack, 2008; Taylor and Baker, 1994), and the existence of the moderating effects was ignored. Two streams of literature suggest that there should be alternative relationship patterns: the one stream is from the zone-tolerance theory and another stream is based on Herzberg's two-factor theory (Pollack, 2008). Some studies have found that both overall satisfaction and repurchase intentions are affected asymmetrically by quality dimension-level performance. For example, Mittal et al. (1998) find that negative performance has a greater impact on a quality dimension than positive performance. Pollack (2008) provide evidence for the existence of non-linear relationships between some service-quality attributes and satisfaction and two types of non-linear patterns are identified. Falk et al. (2010) detect positive asymmetric main effects of functional-utilitarian quality attributes on customer satisfaction, and negative asymmetric effects of hedonic quality characteristics exhibit on customer satisfaction. Therefore, it is not suitable to consider satisfaction only to be a mediator, but ignores satisfaction as a moderator.

However, there is contradictory empirical evidence for the moderating effects of customers' service quality perception and satisfaction on their behavioral intentions. Taylor and Baker (1994) analyzed the relationships among the three constructs in four service sectors (communication, traffic service, entertainment, and health care). They found the moderating effect exists in three of the four sectors (except the health care service), and the influence of satisfaction was more important than perceived service quality. In 1997, they verified the moderator role of satisfaction again in both for-profit and not-for-profit hospital settings (Baker and Taylor, 1997). Although the results support the perspective that satisfaction is more closely related to consumer behaviors than quality perceptions, there is still no significant moderating effect in the two types of hospital settings. Bou-Llusar et al. (2001) selected the ceramic industry to test the relationships among quality perception, satisfaction, and behavioral intentions. Their results show that satisfaction acts as a mediator in the relationship between perceived quality and behavioral intentions, but no evidence reveals the existence of the moderating effect. Lin (2005) discussed the existence of the moderating effect in the banking service industry, and the findings revealed that satisfaction moderates the relationship between service quality and behavioral intentions.

\section{Research method}

\subsection{Measures}

Service quality was to evaluate how well patients perceived the level of service received during the process of going hospital. The development of service quality scale was based on original SERVQUAL (Parasuraman et al., 1988), and other revised 
SERVQUALs (see Rohini and Mahadevappa, 2006; Wu et al., 2008). After designing a preliminary questionnaire there were 22 items included. Three healthcare service experts were asked to evaluate the questionnaire and served as expert judges to critically appraise its validity. Some vocabulary revisions were also made during the iterations. The purpose of this process is to achieve cultural equivalence among diverse populations while applying a different cultural questionnaire in a research study. In addition, service quality generally involves distinct facets of service dimensions in different industries, and hence, considering service-quality dimensions based on the industry context would be suitable (Ladhari, 2008). All the items were measured using a seven-point Likert scale $(1=$ strongly disagree, $7=$ strongly agree) (see Appendix).

Patient satisfaction was assessed with two items based on patients' affective responses to the overall experiences of going this hospital (Wu et al., 2008). They were:

(1) "The overall feelings about the health care service in this hospital are better than I expected."; and

(2) "Overall, I am satisfied with the services provided by this hospital".

Behavior intentions was defined as "patients' potential behaviors likely to be triggered by service quality and satisfaction" (Zeithaml et al., 1996). Five items, which are modified from Zeithaml et al. (1996)'s scale, were used to operationalize behavioral intentions:

(1) "I am willing to recommend this hospital to others who seek my advice".

(2) "I will encourage my friends and relatives to go to this hospital".

(3) "If I need medical service in the future, I will consider this hospital as my first choice".

(4) "If I need medical service in the future, I will go to this hospital more frequently".

(5) "If I feel sick in the next few years, I will go to this hospital less frequently (r)."

All the items of patient satisfaction and behavioral intentions were measured on seven-point Likert scales $(1=$ strongly disagree and $7=$ strongly agree). Finally, since a premise of social psychological theory supports that patients' differences influence their attitudes (Tucker, 2002), individual patient characteristic, which include gender, age, education, personal average monthly income, and frequency of going hospital, are considered as control variables in this study.

After designing the questionnaire, a pilot test was conducted using twenty attendees selected within a regional hospital. Seven days after the first data collection, all the pilot samples were asked to complete the questionnaire a second time without reviewing any reference to the data from the first collection. Minor changes to the questionnaire were made accordingly for appropriateness of wordings, contents, and structures. The feedback was helpful in refining the quality of the measures.

\subsection{Sampling}

The target population for this study was the outpatients derived from the Around Taiwan Health Care Alliance (ATHCA), which have 12 member hospitals in 2007. The alliance's primary purposes are to serve communities throughout Taiwan and to develop high quality healthcare services. Its member hospitals distribute in different

\section{Perceived service} quality

95 
LHS

24,2

96

districts in Taiwan and they all belong to the regional-hospital level (the second-ranking level). Since the intermediate area of healthcare services has not been analyzed in detail and it becomes increasingly important (Etgar and Fuchs, 2009), this study explores more about how perceived service quality and satisfaction influence behavioral intentions for healthcare services.

Since the objective of the survey was to obtain similar numbers of subject structures across different regions in Taiwan, rather than the subjects' representativeness of a specific hospital, each hospital was dispatched 100 questionnaires and the data was collected through convenience sampling. Convenience sampling was deemed appropriate because the purpose of this study was not to provide point and interval estimates of the variables, but to explore the relationships among the variables (Espinoza, 1999). Trained personnel randomly selected outpatients in the area where outpatients waited for taking medication after the whole process of seeing doctors. A total of 665 completed responses were received from 1,200 interviewed subjects and a satisfactory response rate of 55.42 percent was achieved. The respondents were composed of slightly more women (59.3 percent) than men (40.7 percent). Their ages mainly lie between 21-40 years old (55.4 percent), their education level mainly lays at college level (61.8 percent) and their personal average monthly income is largely less than N.T.50,000 (70.6 percent). As to the frequency of going the target hospitals, 59.5 percent of subjects went to hospital more then five times and the frequencies were from two to five for 29.9 percent of the subjects. These frequencies show that the selected subjects are qualified to evaluate service quality of these hospitals and hence, these responses could raise reliability of this study.

\section{Analysis and results}

\subsection{Measurement analysis}

To investigate the reliability of the scales, Cronbach's alpha was computed. Nunnally (1978) presented a rule of thumb, stating that alpha levels higher than 0.70 indicate internal consistency among the items of a scale. After this step, all corrected item-to-total correlation are higher than 0.5 and therefore, no item was deleted (Lin et al., 2003).

Exploratory factor analysis was then performed on the raw scores of the items to identify the factors that could parsimoniously describe the data. The principal component factoring was applied. To make the extracted factors interpretable, the varimax rotation method was performed and the number of factors was determined based on the eigenvalue criterion $(\lambda>1)$. Four factors were selected from service quality. To further improve the distinction between factors, items that had factor loadings greater than 0.4 on two or more factors were removed from the measurement (Lin et al., 2003). After these procedures, two items (SQ17 and SQ20 (italicized in the Appendix)) were deleted and hence, a set of 20 items across the four factors for perceived service quality were used in the following process. After a closer examination of the loading on the factors, a name was given to each factor according to the content of the variables making the greatest contribution to each of the dimensions. The four components of service quality are named as "Reliability," "Responsiveness," "Assurance," and "Empathy," respectively (see Table I). Reliability involves the hard and soft factors to provide the promised service dependably and accurately. Responsiveness involves service providers' willingness to help patients and to provide 


\begin{tabular}{|c|c|c|c|c|c|}
\hline \multirow{2}{*}{$\begin{array}{l}\text { Variable } \\
\text { Factors }\end{array}$} & \multicolumn{4}{|c|}{ Service quality perception } & \multirow{2}{*}{ quality } \\
\hline & Reliability & Responsiveness & Assurance & Empathy & \\
\hline \multicolumn{6}{|l|}{ Items } \\
\hline SQ3 & 0.82 & & & & \multirow{9}{*}{97} \\
\hline SQ4 & 0.80 & & & & \\
\hline SQ2 & 0.77 & & & & \\
\hline SQ1 & 0.75 & & & & \\
\hline SQ5 & 0.73 & & & & \\
\hline SQ6 & 0.69 & & & & \\
\hline SQ7 & 0.65 & & & & \\
\hline SQ8 & 0.64 & & & & \\
\hline SQ9 & 0.59 & & & & \\
\hline SQ11 & & 0.86 & & & \\
\hline SQ12 & & 0.86 & & & \\
\hline SQ13 & & 0.85 & & & \\
\hline SQ10 & & 0.70 & & & \\
\hline SQ21 & & 0.67 & & & \\
\hline SQ22 & & 0.58 & & & \\
\hline SQ14 & & & 0.83 & & \\
\hline SQ15 & & & 0.83 & & \\
\hline SQ16 & & & 0.63 & & \\
\hline SQ19 & & & & 0.88 & \\
\hline SQ18 & & & & 0.88 & Table I. \\
\hline Eigenvalue & 7.78 & 3.80 & 1.18 & 1.02 & Factor loadings and \\
\hline Cumulative $\%$ of variance explained & 38.90 & 57.88 & 63.75 & 68.84 & Cronbach's alphas of \\
\hline Cronbach's alpha & 0.92 & 0.88 & 0.85 & 0.94 & service quality perception \\
\hline
\end{tabular}

prompt response. Assurance involves service providers' courtesy and ability to covey trust and confidence. Empathy involves the provision of caring, individualized attention to patients. As the result, the alphas respectively were $0.92,0.88,0.85$, and 0.94 for the four dimensions of service quality; 0.92 for patient satisfaction; and 0.91 for behavioral intentions. These values suggest a high internal consistency among the items and with their related constructs.

Based on the results of factor analysis, the values of these three manifest variables are determined by calculating the averages in the dimensional questions.

\subsection{Hierarchical regression analysis}

Hierarchical regression analysis (HRA) was used to assess the statistical significance of the moderating effects. Both full and restricted models were developed for this analysis, and the hypothesized moderating and main effects were examined by comparing of the full- and restricted- regression models (Murry and Dacin, 1996). The constituent variables were mean-centered before creating the moderating terms to eliminate multicollinearity (Aiken and West, 1991). The variance inflation factors were well below the cutoff of 10, which suggests that multicollinearity is not a problem (Neter et al., 1990).

The whole procedure included three steps. An initial regression with the control variables was run in the first step, main variables were added (four factors of service quality and satisfaction) in the second step, and the hypothesized moderators were added in the last step. The results of a series of hierarchical models were reported in Table II. 


\section{LHS \\ 24,2}

98

\begin{tabular}{|c|c|c|c|c|c|c|}
\hline \multirow[b]{2}{*}{ Dependent variable (behavioral intention) } & \multicolumn{2}{|c|}{ Step 1} & \multicolumn{2}{|c|}{ Step 2} & \multicolumn{2}{|c|}{ Step 3} \\
\hline & $b$ & $t$ & $b$ & $t$ & $b$ & $t$ \\
\hline \multicolumn{7}{|l|}{ Control variables } \\
\hline Gender & -0.10 & -1.11 & -0.07 & -1.24 & -0.08 & -1.51 \\
\hline Age & 0.16 & $3.86^{*}$ & 0.02 & 0.84 & 0.02 & 0.79 \\
\hline Education & -0.07 & -1.63 & 0.00 & -0.01 & 0.00 & 0.04 \\
\hline Income & 0.06 & 1.23 & 0.03 & 0.99 & 0.03 & 0.90 \\
\hline Frequency & 0.29 & $4.51^{*}$ & 0.18 & 4.62 & 0.18 & 4.55 \\
\hline \multicolumn{7}{|l|}{ Main effects } \\
\hline Reliability (Rel) & & & 0.18 & $4.31^{*}$ & 0.18 & $4.14^{*}$ \\
\hline Responsiveness (Res) & & & 0.15 & $5.67^{*}$ & 0.14 & $5.31 *$ \\
\hline Assurance (Ass) & & & 0.18 & $4.77^{*}$ & 0.16 & $4.30 *$ \\
\hline Empathy (Emp) & & & 0.01 & 0.56 & 0.01 & 0.67 \\
\hline Satisfaction (Sat) & & & 0.48 & $15.93^{*}$ & 0.49 & $16.25^{*}$ \\
\hline \multicolumn{7}{|l|}{ Interaction effects } \\
\hline Rel $\times$ Sat & & & & & 0.07 & $2.24^{*}$ \\
\hline Res $\times$ Sat & & & & & -0.05 & $-2.57^{*}$ \\
\hline Ass $\times$ Sat & & & & & -0.07 & $-2.25^{*}$ \\
\hline Emp $\times$ Sat & & & & & 0.06 & $4.04 *$ \\
\hline$R^{2}$ & $10.12 \%$ & & $67.68 \%$ & & $69.04 \%$ & \\
\hline$F$-value & $13.11^{*}$ & & $120.82^{*}$ & & $91.27^{*}$ & \\
\hline Incremental $R^{2}$ & & & $57.55 \%$ & & $1.36 \%$ & \\
\hline$F$-value for Incremental $R^{2}$ & & & $205.49^{*}$ & & $6.30^{*}$ & \\
\hline
\end{tabular}

The results of hierarchical regression models

Notes: $b$ means the unstandardized coefficient; ${ }^{*} p<0.05$

4.2.1 Results related to main effects. The result of step 1 showed that the regression model was supported $\left(R^{2}=10.12\right.$ percent, $\left.p<0.001\right)$. According to the regression coefficients, age $(b=0.16, p<0.001)$ and frequency of going hospital $(b=0.29$, $p<0.001$ ) had significant effects on behavioral intentions. Subjects who are aged or usually go hospital have more favorable behavioral intentions to hospitals than who are youthful or occasionally go hospital.

In step 2, all the main variables (four dimensions of service quality perception and satisfaction) were put into the regression model. The results showed that the addition of the main variables increased $R^{2}$ by 57.55 percent $(\Delta \mathrm{F}=120.82, p<0.001)$. The regression model was also supported. Except empathy, all the other main variables have positively related to behavioral intentions. Consequently, the main effects have been supported the prediction that service quality perceptions (including reliability, responsiveness, and assurance) and satisfaction have a direct and positive influence on behavioral intentions.

4.2.2 Results related to the moderating effects. Regarding the moderating effects, adding the moderating terms to the main effects model increased $R^{2}$ by 1.36 percent $(\Delta \mathrm{F}=6.30, p<0.001)$ in the step 3. Therefore, there should be the moderating effects. To assist in the interpretation of interaction, subgroup regression lines were graphed using the mean plus or minus 1 standard deviation (Aiken and West, 1991). In this procedure, the regression equation was algebraically restructured to express the regression of the criterion variable on the predictor variable at various levels of the moderator variables. The moderating effects are plotted in Figure 1. 


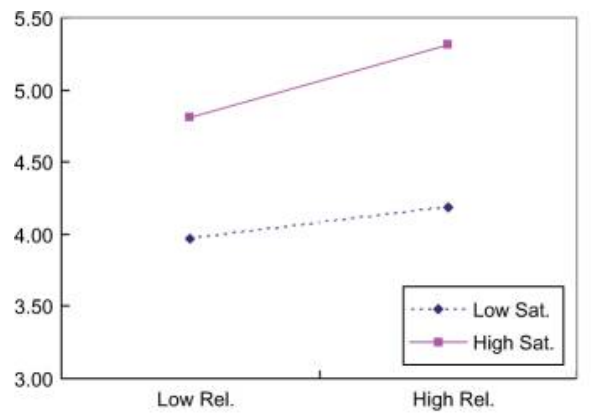

(a)

Satisfaction moderates the relationship between reliability and behavior intention

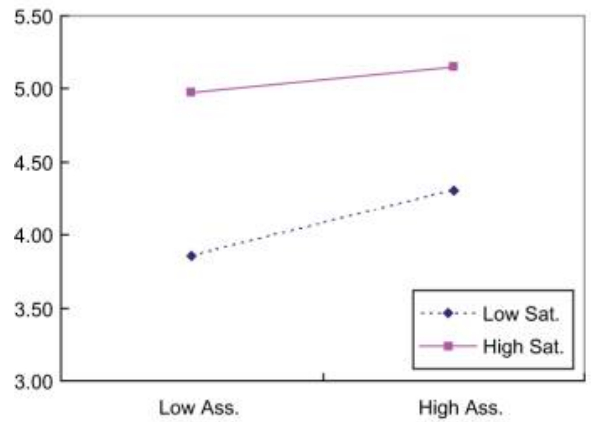

(c)

Satisfaction moderates the relationship between assurance and behavior intention

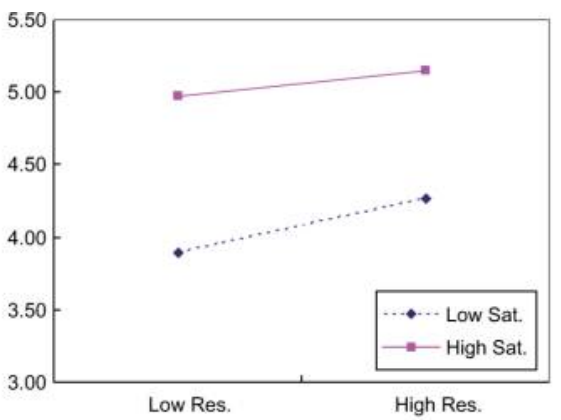

(b)

Satisfaction moderates the relationship between responsiveness and behavior intention

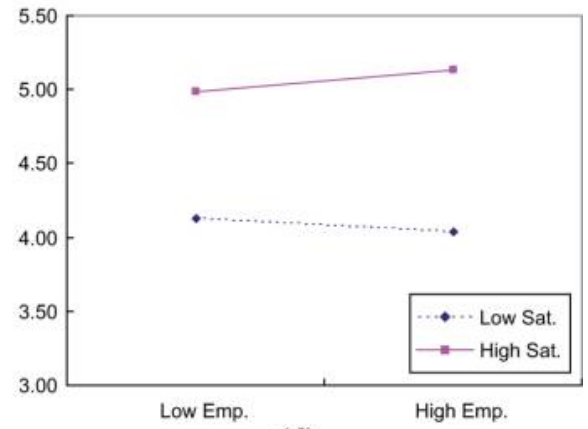

(d)

Satisfaction moderates the relationship between empathy and behavior intention

\section{Perceived service quality}

99

Figure 1.

The moderating effect of satisfaction

According to the regression coefficients, step 3 showed that patient satisfaction positively moderates the relationship between reliability and behavioral intentions $\left(b_{\text {Rel } \times \text { Sat }}=0.07, p<0.05\right)$ and the relationship between empathy and behavioral intentions $\left(b_{\mathrm{Emp} \times \mathrm{Sat}}=0.06, p<0.05\right)$. The positive moderating effect means that patient satisfaction is likely to enhance behavioral intentions when reliability/empathy is high. With high satisfaction, subjects experiencing higher levels of reliability/empathy perception have higher behavioral intentions than those with low satisfaction.

However, the forms of the two moderating effects are different. Based on Sharma et al.' (1981) classification of moderators, satisfaction plays as a "quasi moderator" between reliability and behavioral intentions, but as a "pure moderator" between empathy and behavioral intentions since empathy is not related to behavioral intentions but has interaction with satisfaction. Figure 1(a) showed that satisfaction was like an "amplifier," which shows an increase in the association between reliability and behavior intentions (Jose, 2008). Under the high-satisfaction situation, the higher level of reliability the subjects perceived, the more favorable behavioral intentions the subjects presented. By contract, the level of perceived reliability relatively has few effects on behavioral intentions under the low-satisfaction situation. In Figure 1(d), 
LHS

24,2

100

subjects with high satisfaction are more likely perceive empathy and do well for hospitals than those with low satisfaction. Further, although the relationship between empathy and behavioral intentions is positive for high satisfied subjects, the relationship is slightly negative for low satisfied patient.

On the other hand, patient satisfaction negatively moderates the relationship between responsiveness and behavioral intentions $\left(b_{\text {Res } \times \text { Sat }}=-0.05, p<0.05\right)$ and the relationship between assurance and behavioral intentions $\left(b_{\text {Ass } \times \text { Sat }}=-0.07\right.$, $p<0.05)$. Figure 1(b) and Figure 1(c) show the two moderating effects have similar patterns. Since the estimates of the predictors are both positive $\left(b_{\text {Res }}=0.14, b_{\text {Ass }}=0.16\right.$, and $\left.b_{\mathrm{SAT}}=0.49\right)$ and the moderating effects are negative, the pattern indicates an antagonistic interaction and thus a complementary effect of the predictors (responsiveness and satisfaction) on behavioral intentions (Homburg and Furst, 2005). In other words, satisfaction is like a "blunter", that shows a decrease in the association between responsiveness/ assurance and behavioral intentions (Jose, 2008). Figure 1(b) and Figure 1(c) showed that both responsiveness and satisfaction have positive effect on behavioral intentions. In addition, behavioral intentions is more strongly affected by reliability perception for low satisfied subjects than for high satisfied subjects.

\section{Discussion and implications}

\subsection{Research issues}

The results of this study provide additional insights into the relationship between perceived service quality and behavioral intentions by examing the moderating effects of satisfaction. Prior studies have examined the moderating effects of satisfaction, but there is numerous contradictory empirical evidence. In addition, no significant findings embedded on the hospital settings are shown. Our findings provide support for this notion. First, satisfaction indeed moderates the relationships between service quality and behavioral intentions. Second, a satisfied patient with low reliability/empathy perception will behave more beneficial to hospitals than an unsatisfied patient with high reliability/empathy perception. In conflict with our predictions, responsiveness/assurance and satisfaction present a complementary effect on behavioral intentions. These findings imply that the natures of the moderating effects are not the same for different service quality dimensions.

\subsection{Implications for improving healthcare services}

Intermediate healthcare services have an important role as they treat patients presenting with more complex medical problems compared to those presenting to district hospitals and physician-led clinics and dental clinics. The results of this study strengthen the importance of patients' perceived service quality in intermediate healthcare services. The study shows that patients' perceived service quality and their affective evaluation have non-linear influences on behavioral intentions for the intermediate healthcare services. The findings of this study can help health care providers and managers to have deep understanding about how patients' perceived service quality and satisfaction simultaneously affect behavioral intentions. Managers of health services need to carefully inspect the different quality dimensions of service delivery and their interactions with use satisfaction for several reasons.

First, since satisfaction is able to amplify the influence of perceived reliability on behavioral intentions, reducing patients' perceived risk during the service process is 
important. Actually, patients have little ability to evaluate healthcare quality and hence, they are only able to choose hospitals based on some tangible cues such as physical equipments and facilities. In Taiwan, the NHI program is bound to the hospital accreditation system, which requires hospitals to maintain enough capacity (such as the amounts of human resources, equipments, hospital beds, and so on) of caring patients. These requirements provide the basic reliability (i.e. visible cues) that each patients could have enough health care resources. Therefore, to benefit customers' perceptions of price/quality trade-offs, service providers could find out which tangible elements are helpful to increase patients' perceived reliability and then present these elements through diversified channels. In addition, educating patients about the meanings of these tangible elements is equally important. If a manger just invests physical equipments and facilities without teaching his patients how these investments improve healthcare/service quality, customers may not perceive that quality is improving.

Second, there is a complementary effect of the predictors (responsiveness/assurance and satisfaction) on behavioral intentions. This means sufficient relationship focus and adequate responsiveness/assurance could make patients know that the hospitals really concern what they want, but responsiveness/assurance should not be given as much as possible. A physician who is willing to respond positively to patients' requests for additional tests or medicines may be regarded as unprofessional (Etgar and Fuchs, 2009). Also, requiring frontline employees to give too much responsiveness/assurance may cause them to suppress true feelings and only to show good emotional states. Emotional labor loading completely exhausts frontline employees and affected service quality. Therefore, managers should notice how to balance requirements between patients and employees. How to decide the suitable degree of responsiveness/assurance must consider a hospital capacity (e.g. equipments and human resources). Hospital managers can develops incentive program to attract outstanding members by the internal marketing that can increase responsiveness of service, ability of service and right of service then reduce emotional labor and emotional exhaust. As to the ways to gather market information, to personally visit patients, ask the contact people what patients expect, periodically collect patients' complaint, make organization plan for service failures, and so on are directions that could be considered (Zeithaml et al., 2006).

Finally, these results provide guidance on how to incorporate quality improvement initiatives into service delivery plans. Instead of improving the quality levels on all attributes, managers should first investigate the nature of the relationship for each service dimension (Pollack, 2008). Managers must be aware that patient's satisfaction can be largely changed by enhancing reliability and empathy, whereas favorable behavior intentions can be further develop by the effect of patient satisfaction. In addition, designing the internal environment in terms of responsiveness/assurance is helpful for keeping satisfied patients.

\section{References}

Aiken, L.S. and West, S.G. (1991), Multiple Regression: Testing and Interpreting Interactions, Sage, Newbury Park, CA.

Baker, T.L. and Taylor, S.A. (1997), "Patient satisfaction and service quality in the formation of customers' future purchase intentions in competitive health service settings", Health Marketing Quarterly, Vol. 15 No. 1, pp. 1-15.

\section{Perceived service quality}

101 


\section{LHS \\ 24,2}

102

Boshoff, C. and Gray, B. (2004), "The relationships between service quality, customer satisfaction and buying intentions in the private hospital industry", South African Journal of Business Management, Vol. 35 No. 4, pp. 27-37.

Bou-Llusar, J.C., Camison-Zornoza, C. and Escrig-Tena, A.B. (2001), "Measuring the relationship between firm perceived quality and customer satisfaction and its influence on purchase intentions", Total Quality Management \& Business Excellence, Vol. 12 No. 6, pp. 719-34.

Bowers, M.R., Swan, J.E. and Koehler, W. (1994), "What attributes determine quality and satisfaction within health care delivery?”, Health Care Management Review, Vol. 19 No. 4, pp. 49-55.

Espinoza, M.M. (1999), “Assessing the cross-cultural applicability of a service quality measure: a comparative study between Quebec and Peru", International Iournal of Service Industrv Management, Vol. 10 No. 5, pp. 449-68.

Etgar, M. and Fuchs, G. (2009), "Why and how service quality perceptions impact consumer responses", Managing Service Qualitv, Vol. 19 No. 4, pp. 474-85.

Falk, T., Hammerschmidt, M. and Schepers, J.J.L. (2010), "The service quality-satisfaction link revisited: exploring asymmetries and dynamics", Lournal of the Academy of Marketing Science, Vol. 38, pp. 288-302.

Frazier, P.A., Tix, A.P. and Barron, K.E. (2004), "Testing moderator and mediator effects in counseling psychology research", Lournal of Counseling Psvchology, Vol. 51 No. 1, pp. 115-34.

Fullerton, G. and Taylor, S. (2002), "Mediating, interactive, and non-linear effects in service quality and satisfaction with services research", Canadian Iournal of Administrative Sciences, Vol. 19 No. 2, pp. 124-36.

Goldstein, S.M. and Schweikhart, S.B. (2002), "Empirical support for the Baldrige Award framework in US hospitals", Health Care Management Review, Vol. 27 No. 1, pp. 62-75.

González, M.E.A., Comesaña, L.R. and Brea, J.A.F. (2007), "Assessing tourist behavioral intentions through perceived service quality and customer satisfaction", Lournal of Business Research, Vol. 60 No. 2, pp. 153-60.

Gooding, S.K.S. (1995), "Quality, sacrifice, and value in hospital choice", Journal of Health Care Marketing, Vol. 15 No. 4, pp. 24-31.

Homburg, C. and Furst, A. (2005), "How organizational complaint handling drives customer loyalty: an analysis of the mechanistic and the organic approach", Lournal of Marketing, Vol. 69 No. 3, pp. 95-114.

Jose, P. (2008), "Statistical moderation", paper presented at the Society of Australasian Social Psychologists (SASP) Conference, Wellington, 27 March.

Ladhari, R. (2008), “Alternative measures of service quality: a review”, Managing Service Qualitv, Vol. 18 No. 1, pp. 65-86.

Lin, N.P., Weng, J.C.M. and Hsieh, Y.C. (2003), "Relational bonds and customers' trust and commitment - a study on the moderating effects of web site usage", The Service Industries Lournal, Vol. 23 No. 3, pp. 103-24.

Lin, S.Y. (2005), "The relationship among service quality, satisfaction, and behavioral intentions: an application of hierarchical moderator regression”, Management Review, Vol. 24 No. 2, pp. 1-17 (in Chinese).

Mittal, V., Ross, W.T. and Baldasare, P.M. (1998), "The asymmetric impact of negative and positive attribute-level performance on overall satisfaction and repurchase intentions", Journal of Marketing, Vol. 62 No. 1, pp. 33-47.

Murry, J.P. Jr and Dacin, P.A. (1996), "Cognitive moderators of negative-emotion effects: implications for understanding media context", Iournal of Consumer Research, Vol. 22 No. 4, pp. 439-47. 
Neter, J., Wasserman, W. and Kutner, M.H. (1990), Applied Linear Statistical Models: Regression, Analysis of Variance, and Experimental Designs, Richard D. Irwin, Inc., Homewood, IL.

Nunnally, J.C. (1978), Psychometric Theory, McGraw-Hill, New York, NY.

O'Connor, J.S., Shewchuk, R.M. and Bowers, M.R. (1991), "A model of service quality perceptions and health care consumer behavior", Journal of Hospital Marketing, Vol. 6 No. 1, pp. 69-92.

O'Connor, J.S., Trinh, H.Q. and Shewchuk, R.M. (2000), "Perceptual gaps in understanding patient expectations for health care service quality", Health Care Management Review, Vol. 25 No. 2, pp. 7-23.

Oliver, R.L. (1993), "A conceptual model of service quality and service satisfaction: compatible goals, different concepts", in Teresa, A.S., David, E.B. and Stephen, W.B. (Eds), Advances in Marketing and Management, JAI Press, Greenwich, CT, pp. 65-85.

Olsen, S.O. (2002), "Comparative evaluation and the relationship between quality, satisfaction, and repurchase loyalty", Journal of the Academv of Marketing Science, Vol. 30 No. 3, pp. 240-9.

Parasuraman, A., Zeithaml, V.A. and Berry, L.L. (1985), “A conceptual model of service quality and its implications for future research”, Lournal of Marketing, Vol. 49 No. 4, pp. 44-8.

Parasuraman, A., Zeithaml, V.A. and Berry, L.L. (1988), "SERVQUAL: a multiple item scale for measuring customer perceptions of service quality", Journal of Retailing, Vol. 64 No. 1, pp. $12-40$.

Pollack, B.L. (2008), "The nature of the service quality and satisfaction relationship: empirical evidence for the existence of satisfiers and dissatisfiers", Managing Service Quality, Vol. 18 No. 6, pp. 537-58.

Reidenbach, R.E. and Sandifer-Smallwood, B. (1990), "Exploring perceptions of hospital operations by a modified SERVQUAL approach", Journal of Health Care Marketing, Vol. 10 No. 4, pp. 47-55.

Rohini, R. and Mahadevappa, B. (2006), "Service quality in Bangalore hospitals: an empirical study”, Journal of Services Research, Vol. 6 No. 1, pp. 59-82.

Rust, R.T. and Oliver, R.L. (1994), "Service quality: insights and managerial implications from the frontier", in Rust, R.T. and Oliver, R.L. (Eds), Service Quality: New Directions in Theory and Practice, Sage, New York, NY, pp. 1-19.

Sharma, S., Durand, R.M. and Gur-Arie, O. (1981), "Identification and analysis of moderator variables”, Journal of Marketing Research, Vol. 18 No. 3, pp. 291-300.

Shemwell, D.J., Yavas, U. and Bilgin, Z. (1998), "Customer-service provider relationships: an empirical test of a model of service quality, satisfaction and relationship-oriented outcomes”, International Iournal of Service Industrv Management, Vol. 9 No. 2, pp. 155-68.

Taner, T. and Antony, J. (2006), "Comparing public and private hospital care service quality in Turkey”, Leadership in Health Services, Vol. 19 No. 2, pp. 1-10.

Taylor, S.A. and Baker, T.L. (1994), "An assessment of the relationship between service quality and customer satisfaction in the formation of customers' purchase intentions", Iournal of Retailing, Vol. 70 No. 2, pp. 163-78.

Tucker, J.S. (2002), “The moderators of patient satisfaction”, Journal of Management in Medicine, Vol. 16 No. 2, pp. 48-66.

Wen, C.P., Tsai, S.P. and Chung, W.S. (2008), "A ten-year experience with universal health insurance in Taiwan: measuring changes in health and health disparity", Annals of Internal Medicine, Vol. 148 No. 4, pp. 258-67.

Woodside, A., Frey, L. and Daly, R. (1989), "Linking service quality, customer satisfaction and behavioral intention”, Journal of Health Care Marketing, Vol. 9 No. 4, pp. 5-17. 
LHS

24,2

104
Wu, H.L., Liu, C.H. and Hsu, W.H. (2008), “An integrative model of customers' perceptions of health care services in Taiwan”, The Service Industries Iournal, Vol. 28 No. 9, pp. 1307-19.

Zeithaml, V.A., Berry, L.L. and Parasuraman, A. (1996), "The behavioral consequences of service quality", Journal of Marketing, Vol. 60 No. 2, pp. 31-46.

Zeithaml, V.A., Bitner, M.J. and Gremler, D.D. (2006), Services Management: Integrating Customer Focus across the Firm, McGraw-Hill, New York, NY.

\section{Appendix. Items used in service quality perception}

- This hospital has modern looking equipment (e.g. C.T. Scan, X -Ray, M.R.I. Scan, Tread mill etc.).

- The physical facilities at this hospital are visually appealing (e.g. well maintained reception area, computerized billing and registration facilities, neat and clean pathology, biochemistry labs, hospital rooms etc.).

- Personnel of this hospital are neat in appearance (e.g. staff with uniform and appropriate name badges, professional appearance of staff etc.).

- Materials associated with out-patient services (e.g. clean and comfortable environment with good directional signs, informative brochures about services, stretcher, wheel chairs etc.) are visually appealing in this hospital.

- When this hospital promises to do something by a certain date (e.g. laboratory exams, follow-up checks, out-patient surgery etc.), it does so.

- When a patient has a problem, this hospital shows a sincere interest in solving it.

- This hospital is dependable (e.g. provide services at appointed time, record error-free or fast revised documents, perform treatment and care correctly etc.).

- This hospital provides its services at the time it promises to do so (e.g. emergency care, casualty services etc.).

- This hospital is competent in providing accurate services (e.g. correct records, accurate diagnosis, timely treatment etc.).

- Personnel of this hospital tell patients exactly when services are provided.

- Personnel of this hospital give prompt services to patients.

- Personnel of this hospital are always willing to help patients.

- Personnel of this hospital are never too busy to respond to patients' requests.

- Behavior of personnel in this hospital instils confidence in patients (e.g. convincing explanations etc.).

- Patients are able to feel safe while they receive services from personnel of this hospital.

- Personnel of this hospital are consistently courteous with their patients.

- Personnel of this hospital have the knowledge and skills to respond to patients' requirements.

- This hospital gives patients individual attention.

- Personnel of this hospital keep their patients informed and listen to them.

- Personnel of this hospital understand the specific needs of their patients.

- This hospital has the patients' best interest at heart.

- This hospital's operating hours are convenient for all patients and their families. 


\section{About the authors}

Shyh-Jane Li now is the Major Consultant of the Sense Team Creativity Corporation and has been consulting in the areas of organization change, organization development, and human resources management. His clients include business firms and not-for-profit organizations, such as China Steel Corporation, Taiwan Semiconductor Manufacturing Company Limited, China Shipbuilding Corporation, many hospitals, and so on.

Yu-Ying Huang is currently the Specialist in the Management Department at Antai Tian-Sheng Memorial Hospital in Taiwan. As the Assistant Professor in the Faculty of Management and Administration, Macau University of Science and Technology, she had teaching experience in Marketing Management, Services Marketing, and Research Methodology. Now, she is delving into the industrial area to add practical experience and is actively working on research projects related to marketing, service marketing and supply chain management issues in China and Taiwan. Yu-Ying Huang is the corresponding author and can be contacted at: y.y.huang84@hotmail.com

Miles M. Yang is a PhD candidate in Strategy \& Entrepreneurship at the Australian School of Business. His research in behavioral strategy examines how different managerial mental models, business strategies, and policies influence different levels in firm performance.

\section{Perceived service quality}

105

To purchase reprints of this article please e-mail: reprints@emeraldinsight.com Or visit our web site for further details: www.emeraldinsight.com/reprints 


\section{This article has been cited by:}

1. Asma Shabbir COMSATS Institute of Information Technology Islamabad Pakistan Shahab Alam Malik COMSATS Institute of Information Technology Islamabad Pakistan Shujah Alam Malik Universiti Teknologi Malaysia Johar Bahru Malaysia Ton van der Wiele Erasmus University Rotterdam Netherlands Rotterdam Netherlands . 2016. Measuring patients' healthcare service quality perceptions, satisfaction, and loyalty in public and private sector hospitals in Pakistan. International Journal of Quality \& Reliability Management 33:5. . [Abstract] [PDF]

2. Josip Mikulić, Ines Dužević, Tomislav Baković. 2015. Exploring drivers of student satisfaction and dissatisfaction: an assessment of impact-asymmetry and impact-range. Total Quality Management \& Business Excellence 26, 1213-1225. [CrossRef]

3. Tri Widianti Indonesian Institute of Sciences, Tangerang Selatan, Indonesia Sik Sumaedi Indonesian Institute of Sciences, Banten, Indonesia I Gede Mahatma Yuda Bakti Indonesian Institute of Sciences, Tangerang Selatan, Indonesia Tri Rakhmawati Indonesian Institute of Sciences, Tangerang Selatan, Indonesia Nidya Judhi Astrini Indonesian Institute of Sciences, Tangerang Selatan, Indonesia Medi Yarmen Indonesian Institute of Sciences, Tangerang Selatan, Indonesia . 2015. Factors influencing the behavioral intention of public transport passengers. International Journal of Quality \& Reliability Management 32:7, 666-692. [Abstract] [Full Text] [PDF]

4. Ismail Bakan, Tuba Buyukbese, Burcu Ersahan. 2014. The impact of total quality service (TQS) on healthcare and patient satisfaction: An empirical study of Turkish private and public hospitals. The International Journal of Health Planning and Management 29:10.1002/hpm.v29.3, 292-315. [CrossRef]

5. Tonći Lazibat, Tomislav Baković, Ines Dužević. 2014. How perceived service quality influences students' satisfaction? Teachers' and students' perspectives. Total Quality Management \& Business Excellence 25, 923-934. [CrossRef]

6. Muslim AminInternational Business School, Universiti Teknologi Malaysia (UTM-IBS), Kuala Lumpur, Malaysia Siti Zahora NasharuddinInternational Business School, Universiti Teknologi Malaysia (UTMIBS), Kuala Lumpur, Malaysia. 2013. Hospital service quality and its effects on patient satisfaction and behavioural intention. Clinical Governance: An International Journal 18:3, 238-254. [Abstract] [Full Text] [PDF]

7. Zuzana Pecinova, Zuzana EhlovaRelationship with Customers: Empirical Research on Networking in Pharmacies Business 433-442. [CrossRef] 